\title{
Nephroprotectivity of Coccinia indica leaves against gentamycin- induced nephrotoxicity using in vitro and in vivo models
}

\author{
Neelima Satrasala ${ }^{*}$, Dwarakanadha Reddy Peram², Chandra Sekhar Kothapalli Bannoth ${ }^{3}$ \\ ${ }^{1}$ Jawaharlal Nehru Technological University Anantapur, Anantapuramu, India. \\ ${ }^{2}$ Annamacharya College of Pharmacy, Rajampeta, India. \\ ${ }^{3}$ Krishna University, Machilipatnam, India.
}

\begin{tabular}{l}
\hline ARTICLE INFO \\
\hline Received on: $23 / 02 / 2021$ \\
Accepted on: $13 / 04 / 2021$ \\
Available online: $05 / 06 / 2021$ \\
\\
\hline Key words: \\
Nephrotoxicity, gentamycin, \\
Coccinia indica, antioxidants, \\
HEK-293 cells.
\end{tabular}

\section{INTRODUCTION}

Owing to pretty enormous blood movements and a capacity to extract and aggregate the water-soluble toxic chemicals or molecules, the kidney is inclined to medication-persuaded nephrotoxicity (Perazella, 2003 \& 2019). This kind of nephrotoxicity comprises several mechanisms consisting of vascular damage and glomerular as well as tubular damage (Randjelovic et al., 2017). However, the most commonly investigated one is necrosis caused at tubular epithelial cells and damage of glomerular morphology with lessened function (Stojiljkovic et al., 2012). Some of the drugs, such as gentamycin (GT) and cisplatin, are found to reduce the blood flow in the kidney of experimental animals and cause vascular resistance (Chatterjee et al., 2002).

\footnotetext{
"Corresponding Author

Neelima Satrasala, Jawaharlal Nehru Technological

University Anantapur, Anantapuramu, India.

E-mail:neelus1989@gmail.com
}

The word "obligatory nephrotoxin" is given to one of the widely used antibiotics, GT, for bringing nephrotoxicity in human and rats even in small dosages (Adil et al., 2016; Veljkovic et al., 2017). It is an aminoglycoside drug which treats life-threatening infections caused by Gram +ve and Gram -ve bacteria (Al-Majed et al., 2002; Talei et al., 2017; Tavafi and Ahmadvand, 2011; Thomas et al., 2001). 10\%-20\% of all renal failure cases are accounted due to GT, thus confining its usage (Fashola et al., 2000). GT is known to produce reactive oxygen species (ROS) in the kidney causing necrosis in renal proximal tubular cells, in turn causing renal failure (Reiter et al., 2002) and is usually carried out by estimating the increased levels of creatinine in plasma and urea levels in the blood (Cuzzocrea et al., 2002; Reiter et al., 2002). Some of the compounds like melatonin (Kim et al., 2014; Lee et al., 2012), aminoguanidine (Balakumar et al., 2010; Polat et al., 2006), manganese chloride (Ateşşahin et al., 2003), and Arabic gum (Elshama, 2018) are known to avert GT-induced nephrotoxicity. Among them, one with antioxidant agents is known to consistently protect the experimental animals 
against GT-induced renal toxicity (Walker et al., 2009). Despite treating nephrotoxicity, these synthetic chemicals pose secondary side effects and rise major health concerns. This will demand the support of substitute medicines which could offer sustained health. For the same, several Indian herbal medicines are contributing factors, which are explored extensively and still need several efforts.

To mention, extracts of the plant root of Hemidesmus indicus (Kotnis et al., 2004), leaves of Euclea divinorum (Feyissa et al., 2013), flesh and pits of Phoenix dactylifera dates (A1Qarawi et al., 2008), Hygrophila spinose (Bibu et al., 2010), Kalanchoe pinnata pers (Harlalka et al., 2007), Zataria multiflora (Hajihashemi et al., 2018; Hosseinimehr et al., 2011), Ginkgo biloba (Naidu et al., 2000), corn silk (Sepehri et al., 2011), Allium paradoxum (Nabavi et al., 2012), etc. are reported to show their efficacy toward GT-induced renal toxicity. Coccinia indica leaves were investigated for antilithiasis (avoiding kidney stones formation) by Kumar et al. (2014). Gurukar et al. (2013) have used the fruits and leaves of $C$. indica to treat diabetic nephropathy, and have induced diabetes with streptozotocin. However, this work highlighted the same nephroprotective nature in diabetics. However, nephrotoxicity induced by the intake of antibiotics like aminoglycoside was not addressed. Nevertheless, the efficacy of C. indica pertaining to GT-induced nephrotoxicity is not explored as yet. $C$. indica is the most commonly used vegetable in India called as little gourd (Venkateswaran and Pari, 2002). Various parts of the plant possess traditional values for treating diabetes, inflammation, asthma, ulcers, wounds, and many other purposes (Hussain et al., 2010). The plant has been recounted for several biological activities such as hepatoprotective (Vadivu et al., 2008), hypolipidemic (Kumar et al., 1993), antitussive (Pattanayak and Sunira, 2009), antibacterial (Rahuman and Venkatesan, 2008), and anti-diabetic activities (Kamble et al., 1998).

Herein, we report in vitro and in vivo studies for the ethanolic extract of $C$. indica (EECI) leaves for its nephroprotectivity toward GT-induced renal toxicity. The extract was characterized using the high-performance liquid chromatography (HPLC) technique; in vitro studies were carried out to check the cytotoxicity and cytoprotective ability using Human Embryonic Kidney 293 (HEK-293) cell lines. Male Wistar rats were considered for in vivo acute toxicity studies, wherein biomarkers in the blood plasma such as urea, creatinine, alanine transaminase (ALT), aspartate transaminase (AST), and alkaline phosphatase (ALP) were measured. An oxidative stress was estimated by measuring superoxide dismutase (SOD), reduced glutathione (GSH), and catalase (CAT) levels in the kidney. The results were analyzed by histopathological observations and statistical estimations.

\section{MATERIALS AND METHODS}

\section{Chemicals}

GT was procured from Waksman Selman Pharmaceuticals Pvt. Ltd., Anantapur, India. HEK-293 cell lines were purchased from The National Centre for Cell Science, Pune. Fetal bovine serum, DMEM-high glucose, 3-(4,5-Dimethylthiazol-2-yl)-2,5Diphenyltetrazolium Bromide (MTT) reagent, and biochemical kits were acquired from Himedia Laboratories, Mumbai, India.
Dimethylsulfo-oxide (DMSO) and silymarin were acquired from Sigma-Aldrich (St. Louis, MO). Several other chemicals along with ethanol were purchased from standard chemical vendors.

\section{Plant material}

Fresh green leaves of $C$. indica were taken from Sidhavatam fields, YSR Cuddapah Dist, Andhra Pradesh. The identification and authentication of collected leaves were carried out by Dr. K. Madhava Chetty, Dept. of Botany, S.V. University, Tirupathi. A voucher specimen no. 1061 was deposited at the Department of Pharmacology, Vasavi Institute of Pharmaceutical Sciences, Vasavi Nagar, Andhra Pradesh, India.

\section{Preparation of EECI leaves}

Collected and identified plant leaves were washed several times with water to remove the dirt on them. Washed leaves were then dried under the shadow and powdered with the help of a blender. $850 \mathrm{~g}$ of powder was defatted in a soxhlet for 24 hours consuming petroleum ether and then dried again. It was again subjected to the soxhlet unit to obtain ethanolic extract and dried. The dried extract was screened by HPLC, termed EECI, and was used for further studies.

\section{HPLC analysis}

The obtained EECI was screened for its chemical constituents via HPLC from Agilent Technologies. Acetonitrile:water (40:60) was considered as mobile phase, C18 Inertsil ODS2 reverse phase column was used and the injection volume was $20 \mu \mathrm{l}$. Isocratic elution was considered with PDA detector at $254 \mathrm{~nm}$.

\section{In vitro cytotoxicity analysis}

HEK-293 cell lines of a density of 20,000 cells/wall were cultured in a 96-well plate and left for 24 hours without addition of test agents. After adding test agents, the cells were allowed for 24 hours of incubation at $37^{\circ} \mathrm{C}$ under $5 \%$ carbon dioxide $\left(\mathrm{CO}_{2}\right)$ atmosphere. The used-up media were removed and $0.5 \mathrm{mg} / \mathrm{ml}$ of MTT was further added and incubation continued for 3 hours. The \% viable cells were estimated by using the standard colorimetric technique. Formed purple-colored formazon crystals were dissolved in $100 \mu \mathrm{l}$ of DMSO and ELISA was carried out at $570 \mathrm{~nm}$ to calculate cell viability percentage.

\section{In vitro cytoprotective analysis}

HEK cells of $200 \mu \mathrm{l}$ were grown in a 96-well plate for 24 hours in nonexistence of test agent. GT with appropriate $\mathrm{IC}_{25}, \mathrm{IC}_{50}$, and $\mathrm{IC}_{75}$ concentrations were used to induce toxicity. After adding test compound, the cells were incubated under $5 \% \mathrm{CO}_{2}$ atmosphere for 24 hours at $37^{\circ} \mathrm{C}$. Likewise, in cell viability test, the spent media were added to MTT and analyzed for cytoprotective effect of EECI via ELISA test. Percentage of cell viability was calculated using the following formula: Mean absorbance of sample blank/ mean absorbance of untreated blank $\times 100$.

\section{Animal housing details}

Male Wister rats (24 in number, having an average weight of 200-250 g) were used for the study. The considered rats 
were quarantined and adapted for 14 days. A group of six animals were put into a cage; temperature and humidity were $21^{\circ} \mathrm{C} \pm 3^{\circ} \mathrm{C}$ and $50 \% \pm 10 \%$, respectively. Alternative light and dark cycles were given for 12 hours. The Animal Ethical Committee (IAEC) of NGSM Institute of Pharmaceutical Sciences, Mangaluru (NGSMIPS/IAEC/MARCH-2019/126), was used for the study.

\section{Acute toxicity studies}

Acute toxicity of EECI was analyzed by considering various groups of 10 rats and by following OECD guidelines. $50-2,000 \mathrm{mg}$ of EECI $/ \mathrm{kg}$ of body weight of rats was administered to each rat. The death rate was recorded up to 48 hours. Once analyzed, 200 and $400 \mathrm{mg} / \mathrm{kg}$ of EECI were considered for further studies.

\section{Investigational strategy for GT-induced nephrotoxicity}

Eight days of experiments with randomized experimental rats of four study groups, each with six animals, was designed following the literature (Galdino et al., 2017). The average weight of the group was maintained to not exceed $\pm 20 \%$ of the average weights of all rats. Group I was the control group which received normal saline of $10 \mathrm{ml} / \mathrm{kg} /$ day (i.p.) for 8 days. Group II was infection control, which received GT of $80 \mathrm{ml} / \mathrm{kg}$ of body weight (i.p.) for 8 days. Group III and Group IV were test groups, which received GT along with 200 and $400 \mathrm{mg} / \mathrm{kg}$ body weight of EECI (p.o), which was started before 3 days of GT injection and was proceeded for 8 days.

\section{Assessment of biochemical and antioxidant factors}

The biochemical and antioxidant factors were estimated by following a standard protocol from the literature (Kpemissi et al., 2019). On the 9th day of the experiment, the experimental rats were euthanized. The blood was collected in heparinized tubes and centrifuged for separation of plasma and serum. The kidneys were then removed and washed using cold water, isotonic saline. The excess washing solution was removed by blotting paper. A buffer solution of $\mathrm{pH}$ 7.4, 0.1 M Tris-HCL was used to homogenize tissues and then the quantitative estimation of considered enzymes was carried out using analytical kits. The oxidative stress was also calculated by measuring kidney SOD, $\mathrm{GSH}$, and catalase amounts.

\section{Histopathological examination}

The kidney tissues of every group of rats were stored in formalin solution (10\%) and managed by using paraffin. Thin slices of tissues were stained with hematoxylin and eosin for the histopathological examinations and analyzed further.

\section{Statistical calculations}

One-way analysis of variance, followed by Dunnet's test using Prism Graphpad, was implemented for the statistical calculations of considered parameters of the study. The mean values are represented throughout the study for which the statistical significance of $* p<0.01$ was considered.

\section{RESULTS}

\section{Primary screening of EECI for phytochemical constituents}

The obtained percentage yield in an extraction process of EECI was $12.5 \% w / v$. The HPLC chromatograms at retention times $4.524,4.863,5.307$, and 5.753 minutes confirmed the presence of phytochemical constituents, i.e., flavonoids, terpenoids, tannins ,and phenolic compounds, respectively (Fig. 1). There was also a reasonable amount of anthraquinones, alkaloids, and carbohydrates in EECI. Traces of steroids were also found in the test compound.

\section{In vitro cytotoxicity and cytoprotective effects of EECI}

MTT assay was employed to study the cytotoxic as well as protective effects of EECI over GT-induced toxicity against HEK-293 cell lines. With an aid of silymarin $(15 \mu \mathrm{M})$ as positive control, the efficacy of EECI was analyzed and the results are shown in Figure 2. Figure $2 \mathrm{a}$ and $\mathrm{b}$ shows the cytotoxicity of GT and EECI, respectively. Untreated cell lines were considered as negative control and STD refers to the cells treated with standard drug. Five concentrations of GT $(6.25,12.5,25,50$, and $100 \mu \mathrm{l} /$ $\mathrm{ml}$ ) were considered and the results clearly indicate the decrease in \% cell viability with increase in GT concentration facilitating dose-dependent cytotoxicity of GT. However, there were no

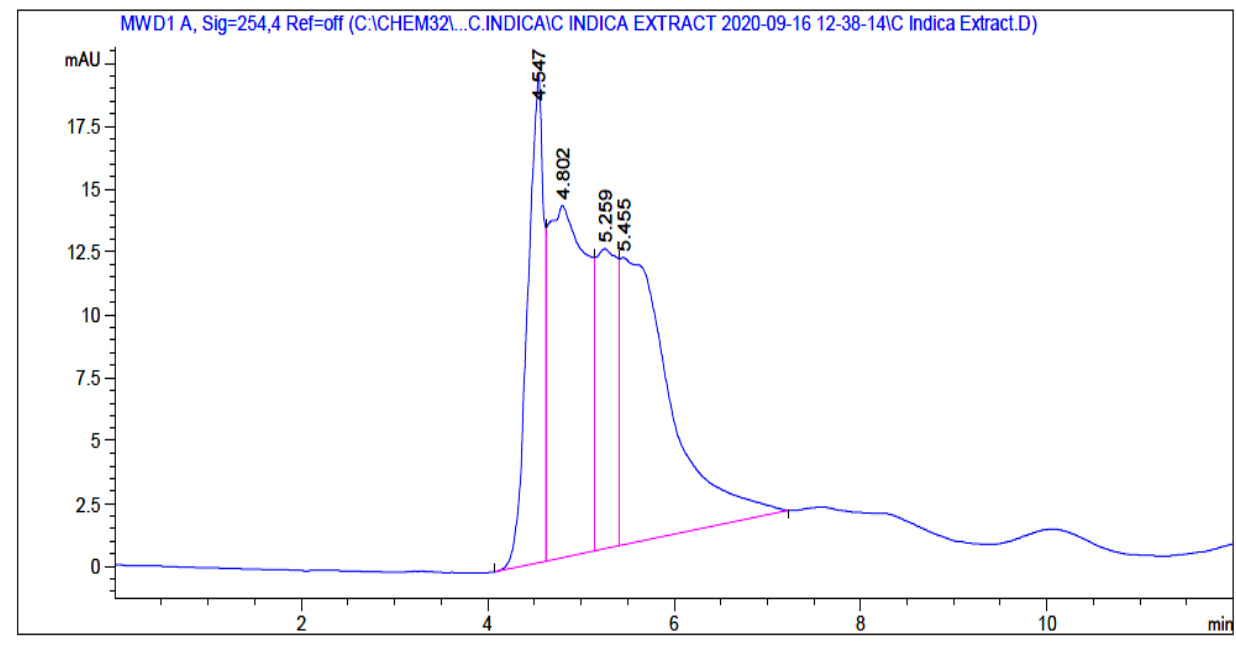

Figure 1. HPLC chromatogram of EECI. 
alterations in the \% cell viability of untreated and STD treated cells. Figure $2 \mathrm{~b}$ shows the cytoprotective nature of the EECI at varied concentrations. Nearly $99.9 \%$ cell viability was observed for $25 \mathrm{mg} / \mathrm{ml}$ of EECI. Cell viability decreased with increasing EECI dosage. For $400 \mathrm{mg} / \mathrm{ml}$ of EECI treatment, the cell viability was nearly $92.5 \%$. However, the changes or decreased cell viability with increased EECI were not so significant, indicating the cytoprotective nature of EECI.

The obtained $\mathrm{IC}_{50}$ value for GT was found to be 35.43 $\mathrm{mg} / \mathrm{ml}$ and same was considered for further studies. Combined effects on the treatment of HEK cells with GT and EECI are shown in Figure 2c. The untreated cells showed 100\% cell viability, whereas the one with GT + STD showed a cell viability of $\sim 98.4 \%$ and it reduced to $\sim 47.8 \%$ for a minimal dosage of EECI $(100 \mathrm{mg} / \mathrm{ml})$ with $\mathrm{IC}_{50}$ of GT. However, $\sim 78.44 \%$ of cell viability was obtained for the ones treated with $400 \mathrm{mg} / \mathrm{ml}$ of EECI, indicating its efficacy for further in vivo studies. The microscopic images of untreated cells, standard drug-treated, GT-alone-treated cells, and EECI + GT treated cells are shown in Figure $2 \mathrm{~d}$. The approximation on the viable cells followed trends that substantiate the obtained combinational effect of EECI + GT.

\section{In vivo nephrotoxicity studies}

The quantification of biomarkers in serum plays a major role in assessing the nephrotoxicity of the test drug. The estimation of the enzymes ALT, AST, and ALP along with creatinine and BUN for all four considered groups is provided in Table 1. Group II, treated with GT alone, showed a sharp increase in the levels of all the considered biomarkers when compared to normal control (Group I). However, we obtained a statistical significance of $* p<$ 0.01 in Group II against Group I. However, with the administration of a lower dose of EECI along with GT (Group III), the levels of
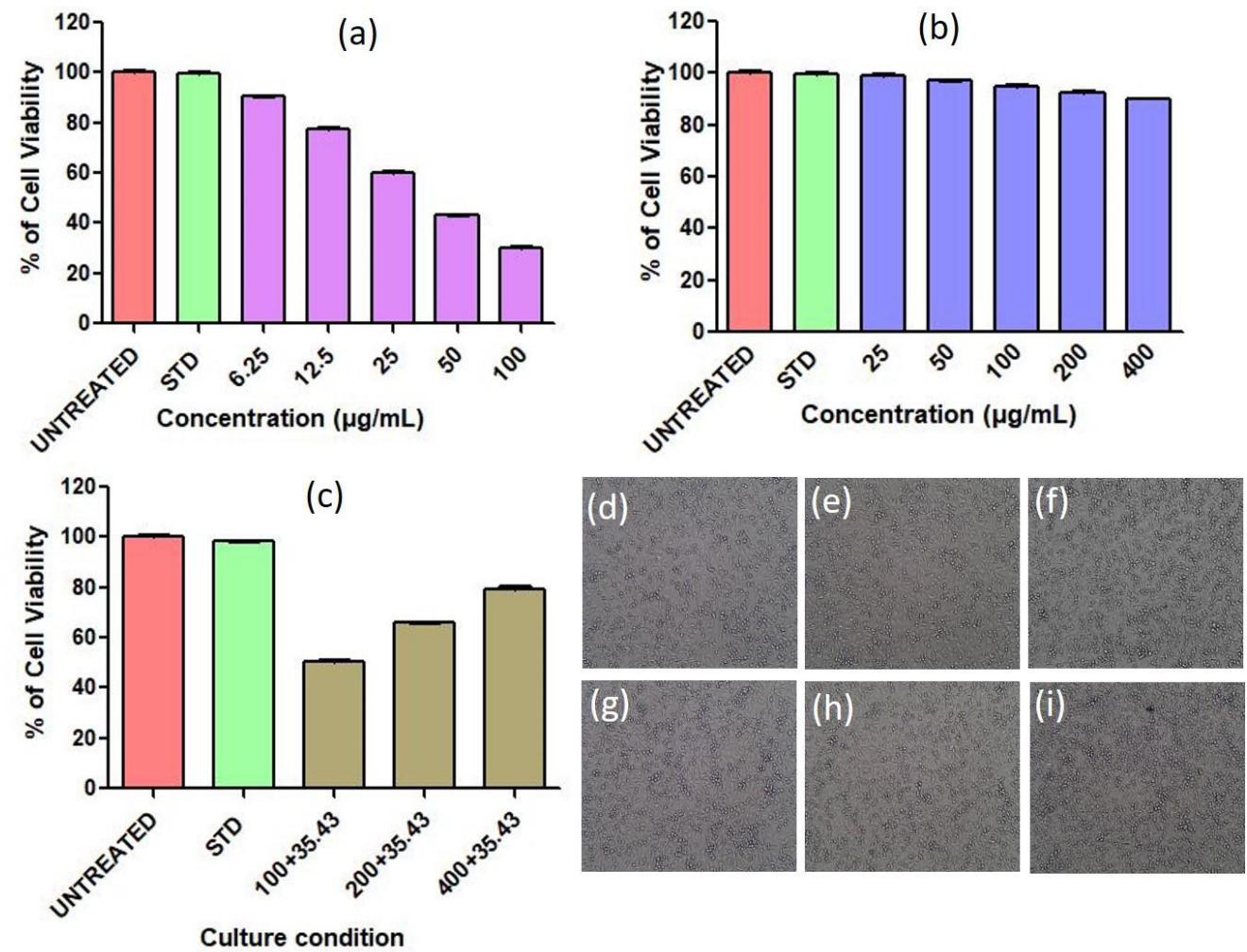

Figure 2. (a) Cytotoxicity of GT against HEK-293 cells; (b) cytoprotectivity of EECI against HEK-293 cells; (c) combinational cytotoxicity against HEK-293 cells; microscopic images of (d) control, (e) HEK standard, (f) GT, (g) EECI $(100 \mu \mathrm{g} / \mathrm{ml})+\mathrm{GT}$, (h) EECI $(200 \mu \mathrm{g} / \mathrm{ml})+\mathrm{GT}$, and (i) EECI $(400 \mu \mathrm{g} / \mathrm{ml})+$ GT-treated cells.

Table 1. Estimated levels of biomarkers in serum for all the four treated groups.

\begin{tabular}{lccccc}
\hline Treatment & ALT(U/l) & AST(U/l) & ALP(U/l) & Creatinine (mg/dl) & BUN (mg/dl) \\
\hline Control & $73.96 \pm 1.377$ & $57.30 \pm 9.220$ & $166.5 \pm 1.225$ & $1.210 \pm 0.019$ & $32.02 \pm 1.576$ \\
GT & $147.7 \pm 0.912^{*}$ & $95.53 \pm 1.644^{*}$ & $264.6 \pm 1.457^{*}$ & $2.631 \pm 0.318^{*}$ & $48.28 \pm 1.507 *$ \\
GT + EECI low dose & $124.6 \pm 1.534^{* *}$ & $76.89 \pm 1.450^{* *}$ & $216.6 \pm 0.721^{* *}$ & $1.013 \pm 0.047 *$ & $45.26 \pm 0.882^{* *}$ \\
GT + EECI high dose & $95.36 \pm 1.676^{* *}$ & $72.68 \pm 0.712^{* *}$ & $192.6 \pm 0.880^{* *}$ & $1.019 \pm 0.020^{* *}$ & $43.35 \pm 1.212^{* *}$ \\
\hline
\end{tabular}

All values are expressed as mean $\pm \mathrm{SD}$, with six animals per group. $(p<0.001)$.

"GT-induced group in comparison with normal group $(p<0.01)$.

**Two experimental groups compared with the GT-induced group. 


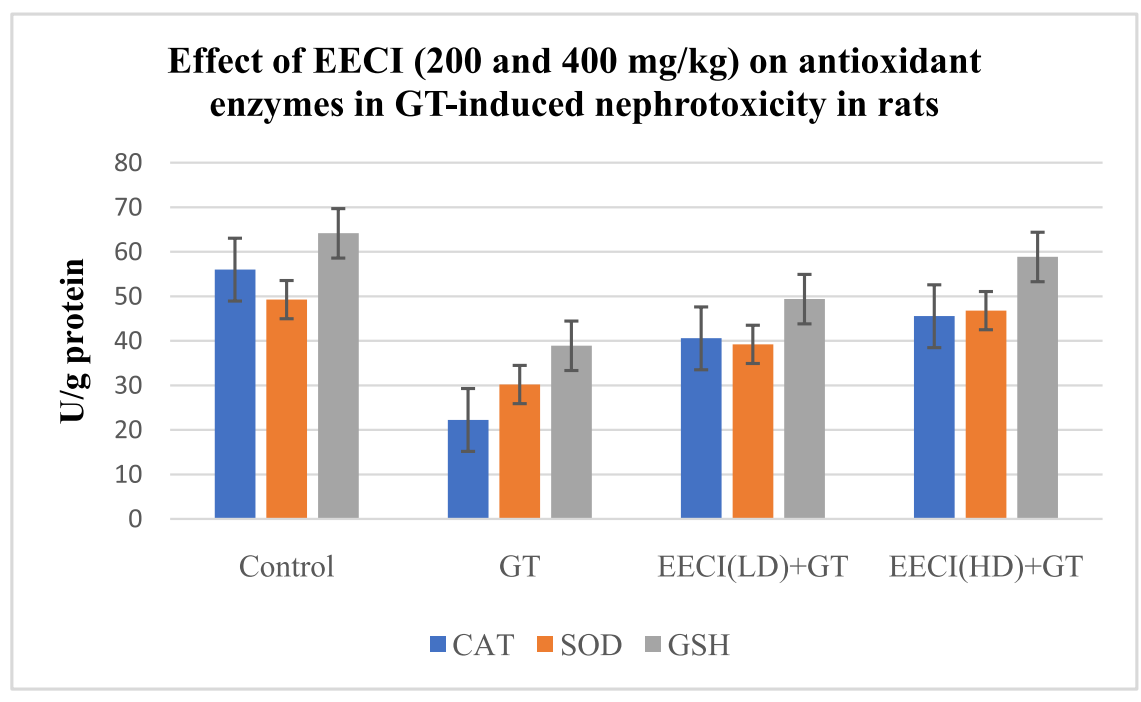

Figure 3. Estimated levels of antioxidant enzymes CAT, SOD, and GSH in control, GT, and EECIadministered groups.

$\operatorname{ALT}(124.6 \pm 1.534 \mathrm{U} / \mathrm{l}), \operatorname{AST}(76.89 \pm 1.450 \mathrm{U} / \mathrm{l}), \operatorname{ALP}(216.6$ $\pm 0.721 \mathrm{U} / \mathrm{l})$, and BUN $(45.26 \pm 0.882 \mathrm{mg} / \mathrm{dl})$ reduced but did not reach the levels of normal control. Besides, the same amounts were estimated to be comparatively better at a higher dose of EECI (Group IV). A statistical significance of $* * p<0.01$ was achieved for test groups compared to the GT-induced group.

Proceeding further, the amounts of GSH, SOD, and catalase antioxidant enzymes were estimated, as shown in Figure 3 , which helped to the extent of kidney damage caused by GT and its treatment with our test drug EECI. In the normal control, the amounts of GSH, SOD, and catalase were $64.16 \pm 0.23 \mathrm{nmol} / \mathrm{g}$, $49.27 \pm 3.12 \mathrm{U} / \mathrm{g}$, and $56.01 \pm 0.56 \mathrm{U} / \mathrm{g}$, respectively, whereas for the negative control, Group II, a significant decrease was observed for all the three factors confirming kidney damage. With an administration of EECI of lower dose $200 \mathrm{mg} / \mathrm{kg}$, a notable increase in them was obtained. Besides, for a treatment with higher dose of EECI, still improved levels of GSH, SOD, and catalase were achieved with a significance factor of $* * p<$ 0.001 when compared to GT-induced toxicity group. The overall results showed an efficiency of EECI in treating the GT-induced nephrotoxicity.

\section{Histopathological inspection}

The histograms of the tissues from the considered four groups are shown in Figure 4. There were no visible alterations or necrosis or degeneration of the tissues for control group (Fig. 4a). Significant alterations and necrosis in the tubular epithelial cells were accounted for in the GT-induced group (Fig. 4b). The group which received lower dose of EECI showed intact cells with feasible regeneration of cells (Fig. 4c). The final one administered with a higher dose of EECI showed insignificant swelling and significant regeneration of cells indicating a cell protective nature (Fig. 4d).

\section{DISCUSSION}

The therapeutic uses of GT are limited due to its welldocumented nephrotoxicity (Cuzzocrea et al., 2002). GT is a classic aminoglycoside and a widely used drug for treating an infection caused by Gram -ve bacteria. Most of the studies have reported the generation of ROS by GT, which induces toxicity in kidneys through a mechanism which could lead to tubular necrosis and decreased glomerular filtration (Karahan et al., 2005). In the present study, damage in renal function is posed by $80 \mathrm{ml} / \mathrm{kg}$ body weight of GT, an aminoglycoside. The nephrotoxicity was achieved by intraperitoneally injecting GT for 6 days continuously, which is an onset way of inducing nephrotoxicity (Wiland and Szechcinski, 2003). The induced renal toxicity by any drug is allied with the accumulation of the drug in the cortex region of the kidney and also on the affinity and kinetics of trapping progression of the drug. It was found that the drug first binds to the cell membrane of proximal tubules and then penetrates into the interior of the cells. The produced ROS then activates NFKB, which is a key mechanism in incepting the inflammation (Lopez-Novoa et al., 2011). However, the spiked rise in creatinine in the plasma is the key indicator of kidney-related infections, although the concentration of blood urea nitrogen is also considered. Besides, the increase in urea levels is observed only after the injury of parenchyma tissue. The present study confirms the GT-induced nephrotoxicity with a significant rise in both plasma creatinine and BUN levels for GTadministered group (Group II) as presented in Table 1.

Besides, before moving to in vivo and in vitro studies, EECI was confirmed for its chemical constituents, such as flavonoids, alkaloids, saponins, and sterols/tripterpenoids, using the HPLC technique and the results are well in agreement with previous reports (Deokate and Khadabadi, 2011; Hussain et al., 2010). The in vitro studies on cytoprotective effects of EECI (Fig. 2b) were studied at varied dosages. At a lower dosage, the $\%$ cell viability for HEK-293 cells was nearly equal to standard drug-treated cells with an indication of cytoprotective effect. The combined effects of GT and EECI also clearly evidenced the increased cell viability when compared with GT-treated ones.

With regard to in vivo studies, as mentioned earlier, the increased levels of creatinine and BUN for infection control, Group II, indicated that nephrotoxicity was induced by GT. 

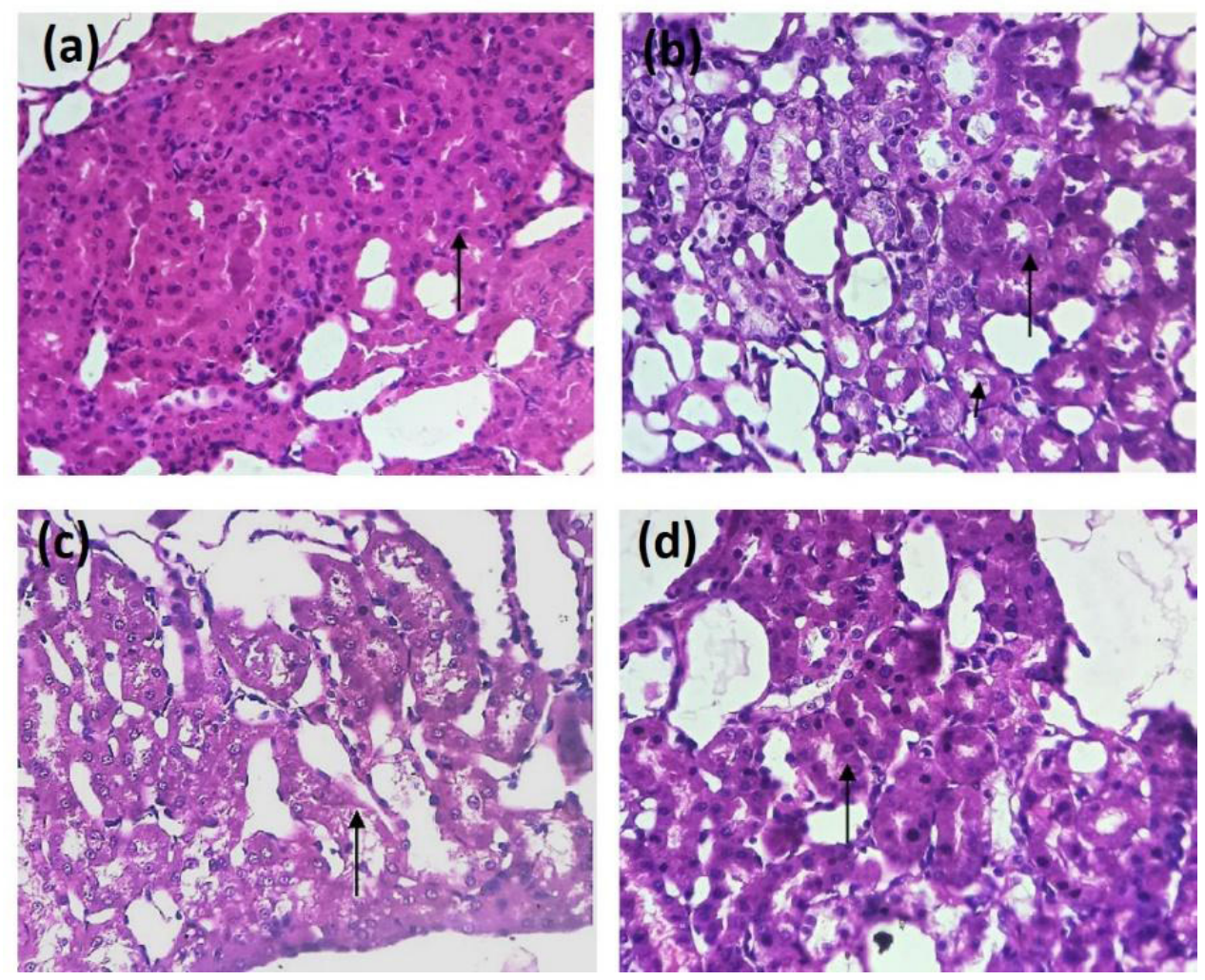

Figure 4. Histograms of kidney tissues of (a) normal group, (b) GT-administered group, (c) lower dose EECIadministered group, and (d) higher dose-administered group.

Furthermore, the groups co-treated with EECI decreased their levels indicating an in vivo nephroprotective effect. In addition, increased amounts of serum enzymes ALP, AST, and ALT for GT-alone-treated group and decreased amounts of the same for GT + EECI-treated groups substantiates the drawn inference. Furthermore, the levels of antioxidant parameters are estimated to investigate upon oxidative stress-induced renal tissue injury. The renal GSH content and the antioxidant enzymes catalase and SOD were significantly reduced in the GT-administered group compared to the control group. GSH- $\mathrm{P}_{x}$ enzyme is known to detoxify $\mathrm{H}_{2} \mathrm{O}_{2}$ to form water and intracellular antioxidant SOD reduces $\mathrm{O}_{2}^{-}$ions to $\mathrm{H}_{2} \mathrm{O}_{2}$ and increases ROS generation. The contribution of ROS oxidative stress involving kidney damage is well established (Fox, 1984), and hence decreases in these enzyme levels, signifying renal injury. With a co-treatment of EECI, the gradual increase in the levels of oxidant enzymes indicate reduced renal damage. Several works support the same trend where an antioxidant melatonin protects the kidneys for which toxicity is induced by GT (Nakakuki et al., 1996). Similarly, carvedilol (Kumar et al., 2000), SOD (Rehman et al., 2001), and many more antioxidants have shown the same trend.

Histograms were also referred to analyze the alterations of kidney tissues. Necrosis was observed for the GT-administered group along with exfoliation of tubular epithelial cells in the cortex region of the kidney. Necrosis was even observed at interstitial nephritis. However, an administration of EECI showed potential to protect GT-induced renal failure. Referring to the literature, analyzing the proposed model with GT and EECI, we infer that as the GT-induced nephrotoxicity is the oxidant-induced kidney damage, EECI remarkably averts oxygen-free radicals allowing reduced oxidative stress; EECI would probably possess antioxidant property which is beneficial for the GT-induced renal damage. EECI is expected to safeguard the tubular epithelial cells of the cortex of the kidney from oxygen free radicals attributed to renal failure and also constrains the oxidized yields formation.

\section{CONCLUSION}

In summary, the EECI leaves was found to possess alkaloids, flavonoids, saponins, and sterols/ tripterpenoids. The proposed model confirmed the nephrotoxicity induced by an aminoglycoside, GT, and the efficacy of EECI against the same. With the literature and by investigation of biomarker levels such as ALT, ATP, AST, creatinine, BUN, oxidative enzymes levels, SOD, GSH, and catalase, EECI is determined to follow the nephroprotective nature against GT by reducing the oxidative stress and following a feature of antioxidant. However, the mechanism needs further exploration for a substantial impression on evolving clinically feasible approaches for real-time applications.

\section{ACKNOWLEDGMENTS}

The authors are grateful to Dr. D. Swarnalatha, Principal, Annamacharya College of Pharmacy, Rajampeta, and Dr. M. Vijay Kumar, NGSM Institute of Pharmaceutical Sciences, Mangaluru, for providing all facilities and their immense support for our work. 


\section{AUTHORS' CONTRIBUTION}

NS and DRP designed and carried out the experiments. NS analyzed the data. NS, DRP, and CSKB together wrote the manuscript. All the authors read and approved the final manuscript.

\section{CONFLICTS OF INTEREST}

The authors report no financial or any other conflicts of interest in this work.

\section{FUNDING}

There is no funding to report.

\section{ABBREVIATIONS}

DMEM: Dulbecco's Modified Eagle Medium;YSR Kadapa: Y.S.Rajasekhar Kadapa; CAT: Catalase;PDA: photodiode array; ELISA: Enzyme linked Immunosorbent Assay; OECD:Organisation For Economic Co-operation and Development; STD: Standard; BUN: Blood Urea Nitrogen; NFkB:Nuclear Factor kappa activated B cells; ATP:Adenosine Triphosphate

\section{ETHICAL APPROVALS}

The studye protocol was approved by the Animal Ethical Committee (IAEC) of NGSM Institute of Pharmaceutical Sciences, Mangaluru (NGSMIPS/IAEC/MARCH-2019/126)

\section{PUBLISHER'S NOTE}

This journal remains neutral with regard to jurisdictional claims in published institutional affiliation.

\section{REFERENCES}

Adil M, Kandhare AD, Dalvi G, Ghosh P, Venkata S, Raygude KS, Bodhankar SL. Ameliorative effect of berberine against gentamicininduced nephrotoxicity in rats via attenuation of oxidative stress, inflammation, apoptosis and mitochondrial dysfunction. Ren Fail, 2016; 38(6):996-1006.

Al-Majed AA, Mostafa AM, Al-Rikabi AC, Al-Shabanah OA. Protective effects of oral arabic gum administration on gentamicin-induced nephrotoxicity in rats. Pharmacol Res, 2002; 46(5):445-51.

Al-Qarawi A, Abdel-Rahman H, Mousa H, Ali B, El-Mougy S. Nephroprotective action of Phoenix dactylifera. in gentamicin-induced nephrotoxicity. Pharm Biol, 2008; 46(4):227-30.

Ateşşahin A, Karahan I, Yilmaz S, Çeribaşi A, Princci I. The effect of manganese chloride on gentamicin-induced nephrotoxicity in rats. Pharmacol Res, 2003; 48(6):637-42.

Balakumar P, Rohilla A, Thangathirupathi A. Gentamicininduced nephrotoxicity: do we have a promising therapeutic approach to blunt it? Pharmacol Res, 2010; 62(3):179-86.

Bibu K, Joy A, Mercey K. Therapeutic effect of ethanolic extract of Hygrophila spinosa T. Anders on gentamicin-induced nephrotoxicity in rats. Indian J Exp Biol, 2010; 48(9):911-7.

Chatterjee P, Mukherjee A, Nandy S. Protective effects of the aqueous leaf extract of Aloe barbadensis on gentamicin and cisplatininduced nephrotoxic rats. Asian Pac J Trop Biomed, 2002; 2(3):S1754-63.

Cuzzocrea S, Mazzon E, Dugo L, Serraino I, Di Paola R, Britti D, Masini E. A role for superoxide in gentamicin-mediated nephropathy in rats. Eur J Pharmacol, 2002; 450(1):67-76.

Deokate U, Khadabadi S. Pharmacology and phytochemistry of Coccinia indica. J Pharmacognosy Phytother, 2011; 3(11):155-9.

Elshama SS. The preventive role of Arabic gum in the treatment of toxicity. Opn Acc Tox Res, 2018; 1:1-27.
Fashola TO, Obatomi DK, Plummer DT. The combined effect of cyclosporine a and gentamicin on enzymuria in the Sprague-Dawley rat. Ren Fail, 2000; 22(3):283-95.

Feyissa T, Asres K, Engidawork E. Renoprotective effects of the crude extract and solvent fractions of the leaves of Euclea divinorum Hierns against gentamicin-induced nephrotoxicity in rats. J Ethnopharmacol, 2013; 145(3):758-66.

Fox RB. Prevention of granulocyte-mediated oxidant lung injury in rats by a hydroxyl radical scavenger, dimethylthiourea. J Clin Invest, 1984; 74(4):1456-64.

Galdino PM, Alexandre LN, Pacheco LF, Junior RSL, de Paula JR, Pedrino GR, Ferreira PM. Nephroprotective effect of Rudgea viburnoides (Cham.) Benth leaves on gentamicin-induced nephrotoxicity in rats. J Ethnopharmacol, 2017; 201:100-7.

Gurukar MSA, Mahadevamma S, Chilkuna ND. Renoprotective effect of Coccinia indica fruits and leaves in experimentally induced diabetic rats. J Med Food, 2013; 16(9):839-46.

Hajihashemi S, Jafarian T, Ahmadi M, Rahbari A, Ghanbari F. Ameliorative effects of Zataria multiflora hydro-alcoholic extract on gentamicin induced nephrotoxicity in rats. Drug Res, 2018; 68(07):387-94.

Harlalka GV, Patil CR, Patil MR. Protective effect of Kalanchoe pinnata pers. (Crassulaceae) on gentamicin-induced nephrotoxicity in rats. Indian J Pharmacol, 2007; 39(4):201.

Hosseinimehr SJ, Mahmoudzadeh A, Ahmadi A, Ashrafi SA, Shafaghati N, Hedayati N. The radioprotective effect of Zataria multiflora against genotoxicity induced by $\gamma$ irradiation in human blood lymphocytes. Cancer Biother Radiopharm, 2011; 26(3):325-9.

Hussain A, Wahab S, Zarin I, Hussain MS. Antibacterial activity of the leaves of Coccinia indica (W. and A) Wof India. Adv Biol Res, 2010; 4(5):241-8.

Kamble S, Kamlakar P, Vaidya S, Bambole V. Influence of Coccinia indica on certain enzymes in glycolytic and lipolytic pathway in human diabetes. Indian J Med Sci, 1998; 52(4):143-6.

Karahan İ, Ateşşahin A, Yılmaz S, Çeribaşı A, Sakin F. Protective effect of lycopene on gentamicin-induced oxidative stress and nephrotoxicity in rats. Toxicology, 2005; 215(3):198-204.

Kim SH, Lee IC, Baek HS, Shin IS, Moon C, Kim SH, Kim JC. Melatonin prevents gentamicin-induced testicular toxicity and oxidative stress in rats. Andrologia, 2014; 46(9):1032-40.

Kotnis MS, Patel P, Menon SN, Sane RT. Renoprotective effect of Hemidesmus indicus, a herbal drug used in gentamicin-induced renal toxicity. Nephrology, 2004; 9(3):142-52.

Kpemissi M, Eklu-Gadegbeku K, Veerapur VP, Negru M, Taulescu M, Chandramohan V, Suhas DS. Nephroprotective activity of Combretum micranthum G. Don in cisplatin induced nephrotoxicity in rats: in-vitro, in vivo and in-silico experiments. Biomed Pharmacother, 2019; 116:108961.

Kumar GP, Sudheesh S, Vijayalakshmi N. Hypoglycaemic effect of Coccinia indica: mechanism of action. Planta Med, 1993; 59(04):330-2.

Kumar KV, Shifow AA, Naidu M, Ratnakar K. Carvedilol: a beta blocker with antioxidant property protects against gentamicin-induced nephrotoxicity in rats. Life Sci, 2000; 66(26):2603-11.

Kumar M, Alok S, Jain SK, Verma A, In-vivo study of antilithiatic activity on the fruits extracts of Coccinia indica (wight \&ARN.) ethylene glycol induced lithiatic in rats. Int J Pharmacognosy, 2014; 6:51-8.

Lee IC, Kim SH, Lee SM, Baek HS, Moon C, Kim SH, Kim JC. Melatonin attenuates gentamicin-induced nephrotoxicity and oxidative stress in rats. Arch Toxicol, 2012; 86(10):1527-36.

Lopez-Novoa JM, Quiros Y, Vicente L, Morales AI, LopezHernandez FJ. New insights into the mechanism of aminoglycoside nephrotoxicity: an integrative point of view. Kidney Int, 2011; 79(1):33-45.

Nabavi SF, Nabavi SM, Moghaddam AH, Naqinezhad A, Bigdellou R, Mohammadzadeh S. Protective effects of Allium paradoxum against gentamicin-induced nephrotoxicity in mice. Food Funct, 2012; 3(1):28-9.

Naidu MUR, Shifow AA, Vijay Kumar K, Ratnakar KS. Ginkgo biloba extract ameliorates gentamicin-induced nephrotoxicity in rats. Phytomedicine, 2000; 7(3):191-7. 
Nakakuki M, Yamasaki F, Shinkawa T, Kudo M, Watanabe M, Mizota M. Protective effect of human ulinastatin against gentamicin-induced acute renal failure in rats. Can J Physiol Pharmacol, 1996; 74(1):104-11.

Pattanayak SP, Sunita P. In vivo antitussive activity of Coccinia grandis against irritant aerosol and sulfur dioxide-induced cough model in rodents. Bangladesh J Pharmacol, 2009; 4(2):84-7.

Perazella MA. Drug-induced acute kidney injury: diverse mechanisms of tubular injury. Curr Opin Crit Care, 2019; 25(6):550-7.

Perazella MA. Drug-induced renal failure: update on new medications and unique mechanisms of nephrotoxicity. Am J Med Sci, 2003; 325(6):349-62.

Polat A, Parlakpinar H, Tasdemir S, Colak C, Vardi N, Ucar M, Acet A. Protective role of aminoguanidine on gentamicin-induced acute renal failure in rats. Acta Histochem, 2006; 108(5):365-71.

Rahuman AA, Venkatesan P. Larvicidal efficacy of five cucurbitaceous plant leaf extracts against mosquito species. Parasitol Res, 2008; 103(1):133.

Randjelovic P, Veljkovic S, Stojiljkovic N, Sokolovic D, Ilic I. Gentamicin nephrotoxicity in animals: current knowledge and future perspectives. EXCLI J, 2017; 16:388.

Rehman K, Wingertzahn MA, Harper RG, Wapnir RA. Proabsorptive action of gum arabic: regulation of nitric oxide metabolism in the basolateral potassium channel of the small intestine. J Pediatr Gastroenterol Nutr, 2001; 32(5):529-33.

Reiter RJ, Tan Dx, Sainz RM, Mayo JC, Lopez-Burillo S. Melatonin: reducing the toxicity and increasing the efficacy of drugs. J Pharm Pharmacol, 2002; 54(10):1299-321.

Sepehri G, Derakhshanfar A, Yazdi Zadeh F. Protective effects of corn silk extract administration on gentamicin-induced nephrotoxicity in rat. Comp Clin Path, 2011; 20(1):89-94; doi: 10.1007/s00580-009-0943-3

Stojiljkovic N, Stoiljkovic M, Mihailovic D, Randjelovic P, Ilic S, Gocmanac-Ignjatovic M, Veljkovic M. Beneficial effects of calcium oral coadministration in gentamicin-induced nephrotoxicity in rats. Ren Fail, 2012; 34(5):622-7.
Talei GR, Mohammadi M, Bahmani M, Kopaei MR. Synergistic effect of Carum copticum and Mentha piperita essential oils with ciprofloxacin, vancomycin, and gentamicin on Gram-negative and Grampositive bacteria. Int J Pharm Investig, 2017; 7(2):82.

Tavafi M, Ahmadvand H. Effect of rosmarinic acid on inhibition of gentamicin induced nephrotoxicity in rats. Tissue Cell, 2011; 43(6):39297.

Thomas T, Galiani D, Brod R. Gentamicin and other antibiotic toxicitiy. Ophthalmol Clin of North Am, 2001; 14(4):611-24.

Vadivu R, Krithika A, Biplab C, Dedeepya P, Shoeb N, Lakshmi K. Evaluation of hepatoprotective activity of the fruits of Coccinia grandis Linn. Int J Health Res, 2008; 1(3):163-168.

Venkateswaran S, Pari L. Effect of Coccinia indica on blood glucose, insulin and key hepatic enzymes in experimental diabetes. Pharm Biol, 2002; 40(3):165-70.

Randjelovic P, Veljkovic S, Stojiljkovic N, Sokolovic D, Ilic I. Gentamicin nephrotoxicity in animals: Current knowledge and future perspectives. EXCLI J. 2017;16:388-399. Published 2017 Mar 24 doi:10.17179/excli2017-165.

Walker PD, Barri Y, Shah SV. Oxidant mechanisms in gentamicin nephrotoxicity. Ren Fail, 2009; 21(3-4):433-42.

Wiland P, Szechcinski J. Proximal tubule damage in patients treated with gentamicin or amikacin. Pol J Pharmacol, 2003; 55(4), 631-7.

How to cite this article:

Satrasala N, Peram DR, Bannoth CSK. Nephroprotectivity of Coccinia indica leaves against gentamycin-induced nephrotoxicity using in vitro and in vivo models. J Appl Pharm Sci, 2021; 11(06):132-139. 